\title{
COOLED TURBINE CANTILEVERED NOZZLE MOUNTING AND SEALING SYSTEM
}

\author{
Leszek Rzeszutek, Grzegorz Kaczmarek \\ General Electric Company Polska Sp. z o.o., Engineering Design Center \\ Krakowska Av. 110/114, 02-256 Warsaw, Poland \\ tel.: $+48606273413,+48668170823$ \\ e-mail:leszek.rzeszutek@ge.com,grzegorz.kaczmarek@ge.com
}

\begin{abstract}
Small advanced turboprop and turboshaft engines, with two-stage high-pressure turbine (HPT), need to meet several challenges. Described herein is an exemplary solution adopted for a cantilevered HPT nozzle mounting and sealing system that helped to meet requirements for size constraint and sealing of split lines and mounting features. Since clearances do not scale down with engine size due to manufacturing tolerances, there is a very limited space available between first and second stage rotors to secure HPT nozzle and to provide means of cooling air supply. Due to small diameters, cavities and size of the parts and assembly access becomes very difficult and precluded the use of typical solutions - like supply air spooilers - known from bigger engines. Relatively larger clearances require also efficient solution for sealing leakage, which was achieved by means of high-temperature braided "rope seals". The nozzle segments have weight effective hook-type outer band mounting to HPT outer casing and are axially retained by HPT shroud with a snap ring. The hook cavities were used as pockets for rope seals that are subsequently compressed during assembly making it more difficult. However, by special design of the pockets and parts engagement sequence, the assembly process was optimized even though it is so called blind assembly. The sealing system function is not only reducing leakages that are detrimental to a turbine efficiency, but also allow for pressurizing the cavity between the nozzle outer band and HPT outer casing with cooling air thus preventing from hot gas ingestion by higher back-flow margin (BFM) resulting in higher durability of the turbine.
\end{abstract}

Keywords: transport, gas turbine, cooled turbine, cantilevered nozzle segment, sealing

\section{Introduction}

Designing smaller gas turbine engine can be in some respects more difficult than a bigger one. It particularly pertains to two-stage cooled turbines where available size and space constraint creates challenges regarding not only cooling scheme and features, but also assembly process, clearances, hot gas path sealing, and cooling air supply. Examples of solutions shown in this article are based on a design of second stage-cooled nozzle, which is a part of $1200 \mathrm{HP}$ advanced turboprop engine's Gas Generator Turbine (GGT), or core engine that includes also a compressor and combustor. The engine has same size class as PT6A. Fig. 1 is showing a part of GGT cross section with the second stage nozzle. The flow path height is in the order of 1 inch. The article focuses on a second stage nozzle outer band mounting and sealing and does not cover inter stage seal arrangement, which is typical, so-called, spoke configuration, engaged with inner band flange slots. Fig. 2 is showing bigger engine example of HPT configuration for comparison.

\section{Description}

The turbine includes a first stage nozzle, rotor, and shroud, and a second stage nozzle, rotor, and shroud, surrounded by an outer annular stationary casing as illustrated on Fig. 1. The shrouds and nozzles are segmented. Each segment of the nozzle includes aerofoils and arcuate inner band and outer band. In this specific example, each nozzle segment is a "doublet" with the band segment spanning two airfoils. 


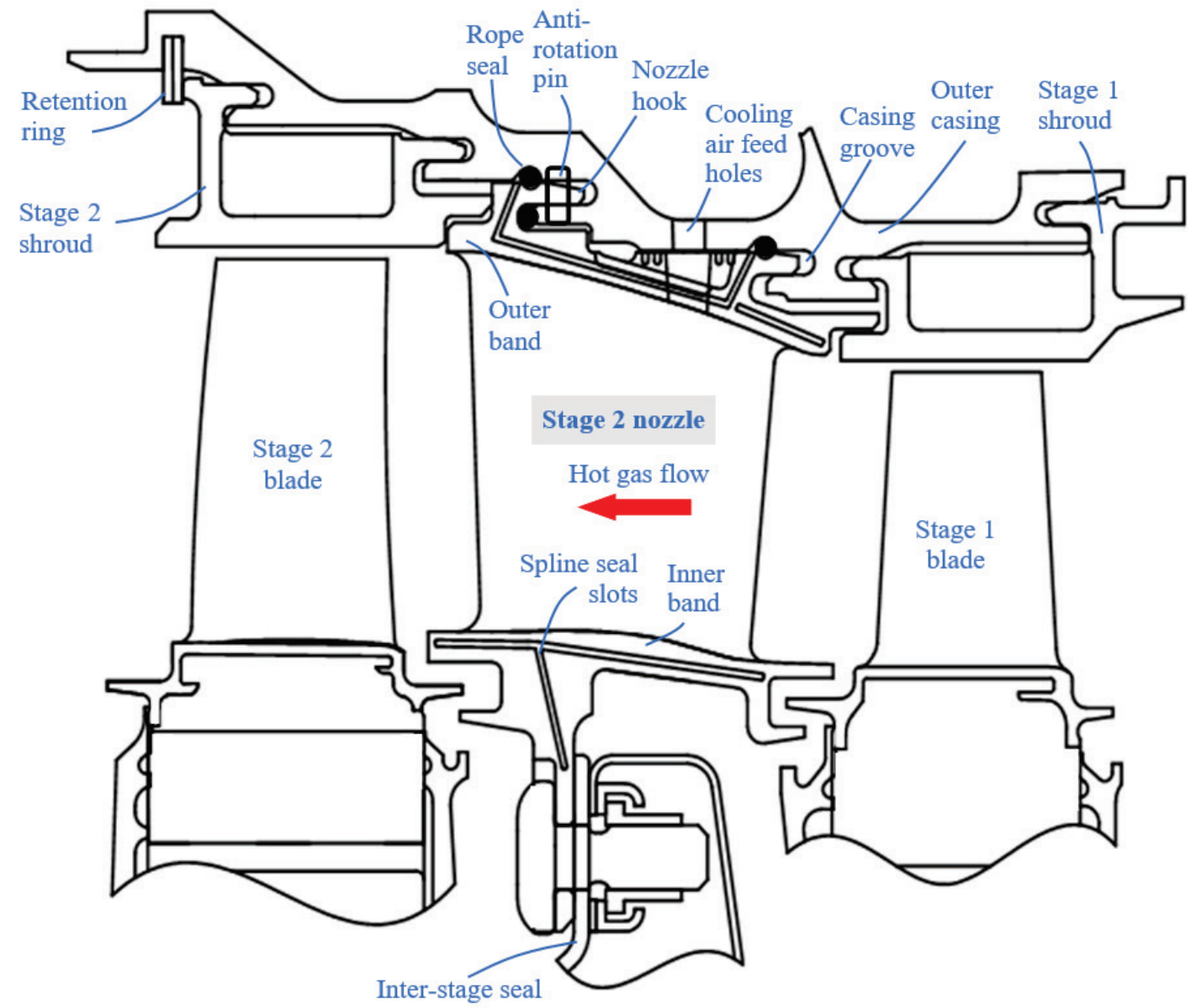

Fig. 1. Partial view of 2-stage GGT

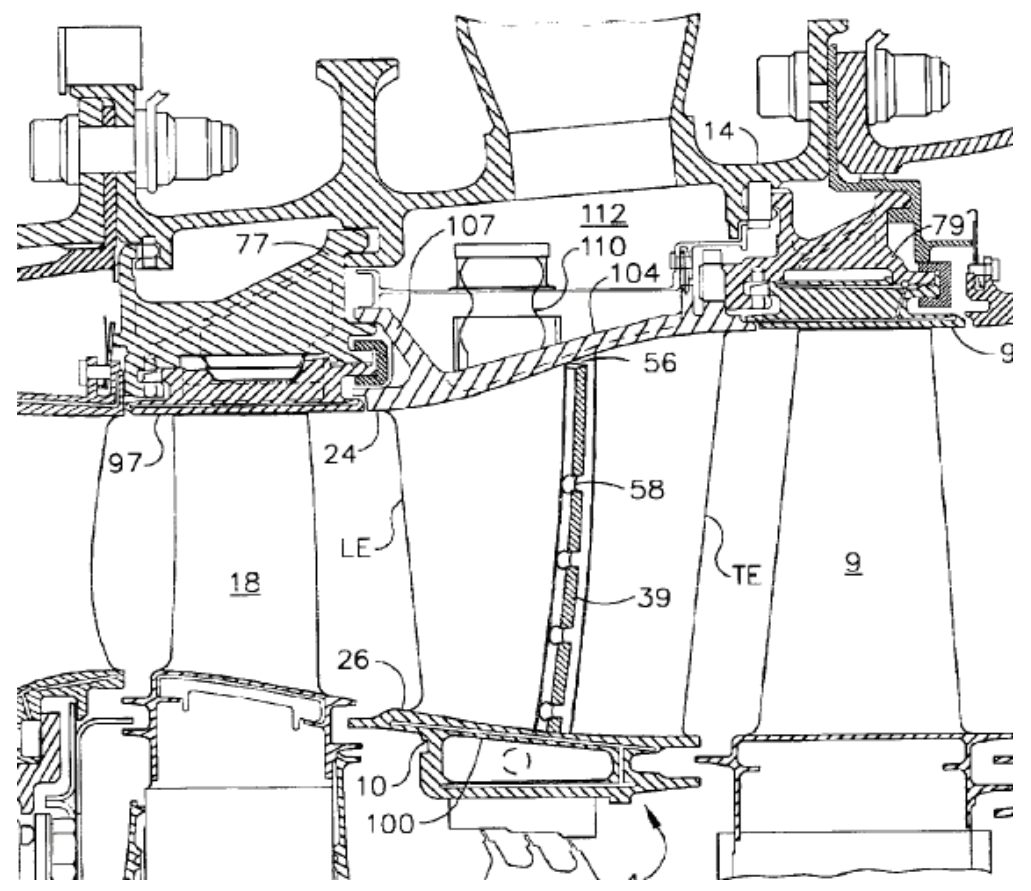

Fig. 2. Commercial engine 2-stage HPT (GE patent US 6,932,568 B2)

Segmented design of cooled nozzle is driven by an increasing thermal load in modern engines, which, together with single crystal casting limitations, precludes reliable $360^{\circ}$ rings nozzle designs. Average metal temperature of the nozzle airfoil is above $1630 \mathrm{deg}$ F ( $888 \mathrm{deg} \mathrm{C})$. On the 
other hand, the consequence of segmented design is that sealing of leakages between nozzle segments, both at inner and outer band end faces is required. This inter-segment gap is required; otherwise, end face contact can occur during steady state or transient operation due to insufficient clearance. It can lead to so called arch-binding, when entire ring of segment forms full $360 \mathrm{deg}$ ring creating uncontrolled loading on to the mounting features and casing.

The nozzle segments cantilevered mounting system is a non-redundant nozzle attachment allowing for thermal expansion while avoiding interference. Each nozzle segment has two hooks, forward and aft, that engage with respective hooks in the outer casing. Aero force is loading the segment and seating it against casing hooks. Tangential component of the aero loading is transferred to the outer structure by means of aft hook slot engaged with the anti-rotation pin in the outer casing hook. Axial retention is achieved by transferring axial load via stage 2 shroud to retention ring in the outer casing.

The nozzle hooks must have clearance in the outer casing grooves to allow for the nozzle outer band thermal chording i.e. deformation caused by a thermal gradient, mainly in radial direction, resulting in the reduction of the band curvature. In consequence, there is a leakage path, which may have detrimental effect on the outer casing durability. Therefore, cantilevered mounting requires protecting outer casing from excessive temperature, which can be done by means of seals at the nozzle to outer casing interface, as shown. Additionally, gaps between nozzles and shrouds should be minimized due to the same reason.

Finally, the nozzle segment air supply has to be ensured. As shown, when the nozzle is mounted to the outer casing using the forward and aft hooks, a small cavity is formed between the outer casing the nozzle outer band. Cooling air is fed by two feedholes in the outer casing. First is to deliver air directly for internal nozzle cooling using a combination of convection, impingement, and/or film cooling. Second hole is providing air directly to the cavity and pressurizing it to prevent hot gas ingestion from the flow path.

\section{Challenges and constraints}

Table 1 is showing concise summary of challenges resulting from specificity of small engines.

Tab. 1. Specificity of small engines

\begin{tabular}{|l|c|c|}
\cline { 2 - 3 } \multicolumn{1}{c|}{} & Manufacturing tolerances do not scale & Size limits \\
\hline Affected characteristics & Increased clearances, gaps, leakages & Hindered access, small size parts \\
\hline Resulting challenges for & Sealing, pressurizing & Assembly \\
\cline { 3 - 3 } & \multicolumn{2}{|c|}{ Interconnected constraints } \\
\hline
\end{tabular}

Manufacturing tolerances do not scale with engine size. They cannot go below certain limit for a given technology, thus are relatively bigger for smaller engines. Difficulties occur particularly in case of small size features (like film cooling holes) but also with clearances from long dimensional stacks. All clearances and leakages are affected because of the same reason. Meeting requirements regarding clearances, interference avoidance, hot gas path sealing and/or flow discouraging (purging stator-rotor buffer cavities) etc., becomes more problematic due to increased dimensional variation and space limitation.

Assembly process is affected by limited access and minimum size limit of parts. However, additional requirements resulting from sealing also affect assembly process and vice versa.

A design should allow assembly process that ensures:

- sealing of inter segment gaps,

- sealing outer band - outer casing interface and pressurizing outer band cavity,

- cooling air supply path. 


\subsection{Sealing of inter segment gaps}

As illustrated on Fig. 3, the forward and aft hooks are placed at different radial locations - aft hook at larger radius - to allow the preassembled second stage nozzle set moved solely in an axial direction to engage the forward and aft grooves in the outer casing during the assembly process. The nozzle is to be preassembled into a ring of segments with installed inter-segment spline seals. The end faces of the band segments have slots formed in them, and the spline seals made of $0.25 \mathrm{~mm}$ thick sheet metal, are placed into the slots. The purpose of the spline seals is to prevent airflow leakage through the end gaps between two adjacent segments. Whole nozzle set assembly eliminates the need of feeder slots to install spline seals in seal slots, and thus helps to not increase leakages.

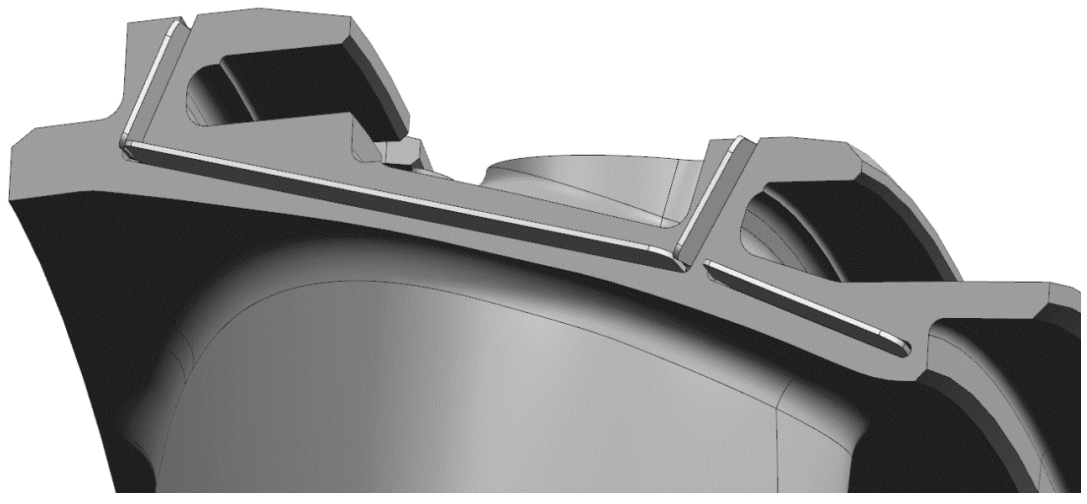

Fig. 3. Spline seals in slots in the nozzle segment outer band end face

\subsection{Sealing outer band - outer casing interface and pressurizing outer band cavity}

The gaps between the forward and aft hooks in the forward and aft grooves may be sealed with continuous circumferential high-temperature seals which are resilient but deformable, for example commercially available "rope seals" aka "braid seals," which could be a silicon or silica-based compliant material surrounded by metallic netting (braided Inconel jacket). A rope seal is fitted into a slot or groove provided and may be temporarily attached by means of adhesive, and then compressed as required and held in place by assembly of the mating component.

The seals have two functions: reducing cooling air leakage that is detrimental for turbine efficiency; and pressurizing the cavity thus preventing flow path hot gas ingestion.

Rope seals that are installed traditionally on top of the forward and aft hook are compressed radially against outer casing interface in respective grooves. Care should be taken to design this interface correctly, such as to avoid rolling, cutting, or other damage when sliding in nozzle segments into position.

Additional seals are used with the aft hooks since it has higher cooling air to flow path gas pressure ratio. This second redundant seal is installed in the hook slot and during the assembly process; it is compressed axially between the hook slot and a portion of the outer casing inboard of the aft slot. Such a seal is easier to install in case of a "blind" assembly process and provides robustness to the system from a back-flow margin (BFM) perspective.

\subsection{Cooling air supply path}

Cooling air supply needs to be assured after the nozzle segments are in position. Access to air supply port in the nozzle outer band would be needed if installing a leak-proof conduit, like traditional spoolies, i.e. short pipe with two spherical bulges pushed into respective sockets in a nozzle and casing. However, such solution is precluded due to lack of access (not enough radial space), and too small size of spoolie. 


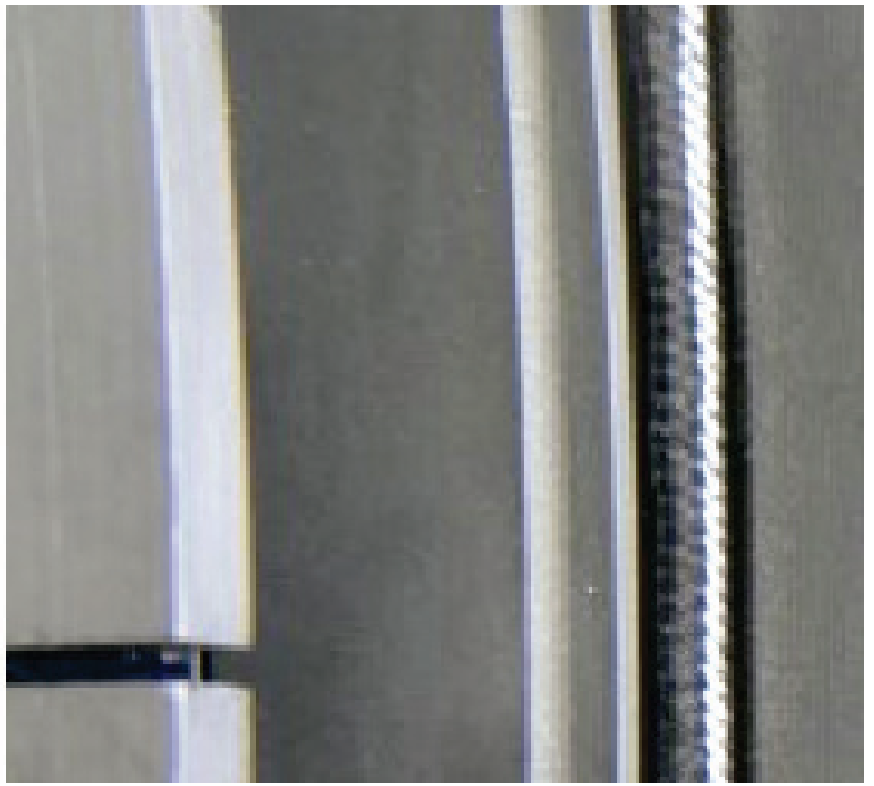

Fig. 4. Rope seal in its pocket

Therefore, a new concept was developed that does not require tight air supply path between the outer casing and the nozzle segment and permits axial direction of nozzle assembly.

Air for internal nozzle cooling is supplied by a feedhole in the outer casing and via nozzle air inlet in the nozzle outer band as shown on Fig. 5. The mating faces of the casing and the inlet interface are spaced such that there is always small gap between them. Air leakages from this interface are limited by both minimizing the gap, and by pressurizing the outer band cavity.

Pressurizing the outer band cavity is done by the second feedhole in the outer casing. A static pressure difference between the nozzle outer band cavity and the nozzle air inlet is nominally minimized. Which facilitates restricting leakage of the cooling air. In off-design conditions, the leakages can be further minimized by adding concentric labyrinth, or compliant seal such as V-seal, W-seal or other, as shown on Fig. 6.

The air leakages of through circumferential rope seals and intersegment spline seals in the outer band were reduced by around 50\% comparing to conventional design, while assuring purging and the same back flow margin.
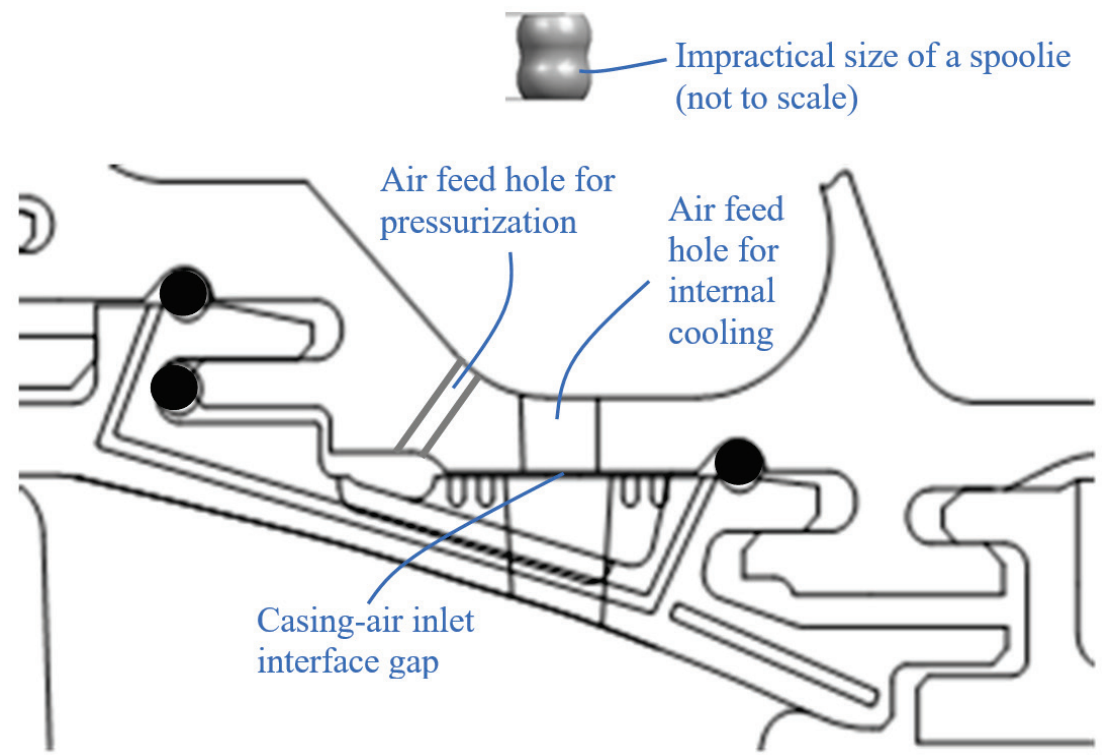

Fig. 5. Cooling air inlet interface 


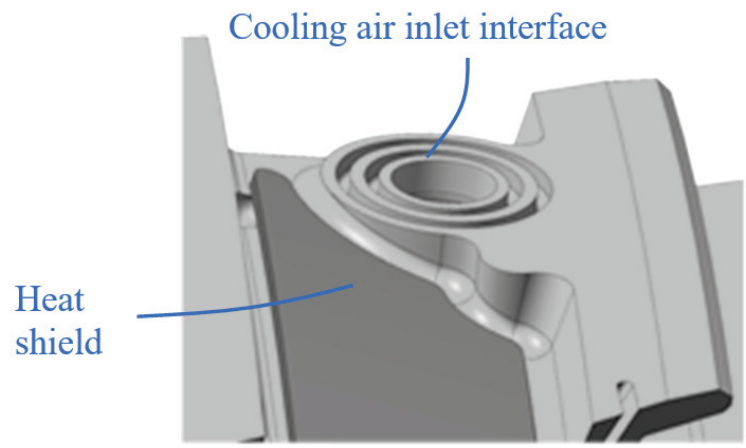

Fig. 6. Nozzle cooling air inlet vs. spoolie

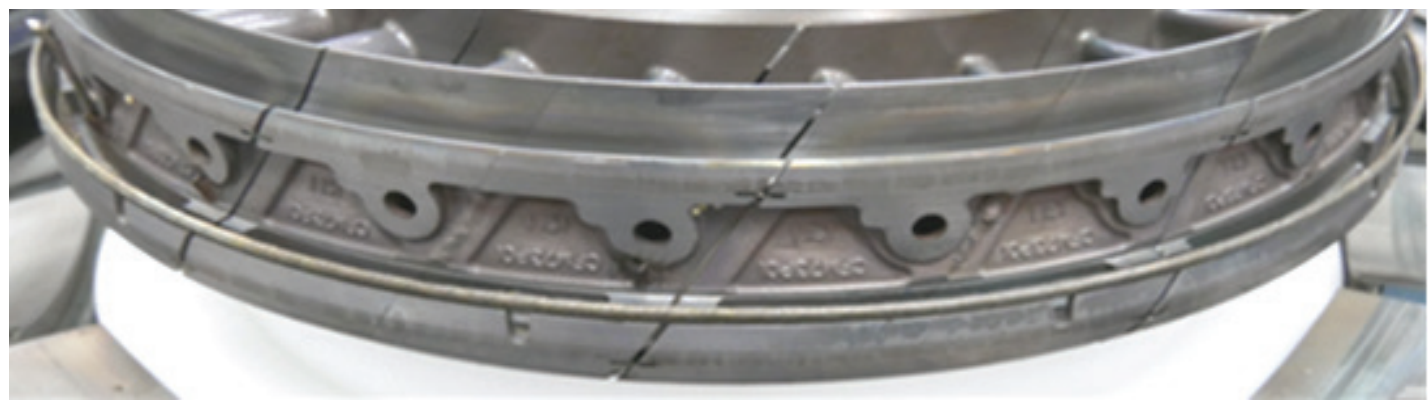

Fig. 7. Set of pre-assembled nozzles and seals

\section{Conclusion}

Proposed cantilevered nozzle mounting and sealing system provides benefits in terms of performance by reduction of air leakages, durability by reduction of hot gas leakages/ingestion, weight and assembleability by simplified design, suited for small engines.

\section{References}

[1] Klimek, K., et al., Turbine Shroud assembly for small turboprop engines, Proceedings of the 7th EASN International Conference on Innovation in European Aeronautics Research, Warsaw 2017.

\section{Unia Europejska \\ Europejski Fundusz Rozwoju Regionalnego}

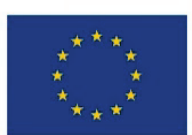

Fundusze Europejskie Inteligentny Rozwój

Research works conducted as part of the project DEVELOPMENT OF COOLING TECHNOLOGY FOR HOT SECTION COMPONENTS IN ROTATING MACHINES WITH REFERENCE TO HIGH-PRESSURE TURBINE BLADES AND VANES

FINANCING AGREEMENT WITH THE NCR\&D POIR.01.01.01-00 D007/16-00 of 12.01.2017

Measure 1.1.1 "Industrial research and development work conducted by enterprises" as part of Priority Axis I "Support for R\&D activity of enterprises" of the Smart Growth 2014-2020 Operational Programme CPV: 73000000-2 (Research and development services and related consultancy services)

Manuscript received 10 July 2019; approved for printing 16 September 2019 